\title{
PENGEMBANGAN APLIKASI PENJADWALAN WISATA HARIAN PADA SMARTPHONE DENGAN PENDEKATAN SCRUM
}

\author{
Yen Lina Prasetio; Novita Hanafiah; Agustinna Yosanny; \\ Catharine Yolanda; Febrina Piecella Musbar; Denny Septianto \\ Computer Science Department, School of Computer Science, Binus University \\ Jl. K.H. Syahdan No. 9, Palmerah, Jakarta Barat 11480 \\ yenlina@binus.edu; nhanafiah@binus.edu
}

\begin{abstract}
The technology development affects people activites especially in this $20^{\text {th }}$ century. Mobile phone is changed into smartphone and travelling becomes a new lifestlye. A Tourism scheduler with a reminder is created from this research to fulfill the new trend of people lifestyle. The travelling data is stored in the system and some information such as the point of interest of an area, hotel, and transportation to reach the area are provided. Waterfall model becomes the method to build this system. Hence, an application that can create a trip for the user is completely built in Blackberry application system, consist of the trip information. The history feature provided in this application can be an advantange for the user to choose the new travelling destination. Moreover, the application has a good interface follow the eight golden rules and has a good performance that helps the tourists/users to create their own schedule and set the reminder for them.
\end{abstract}

Keywords: Smartphone, waterfall model, tourism, Blackberry

\begin{abstract}
ABSTRAK
Perkembangan teknologi mempengaruhi aktivitas manusia terutama pada abad ini. Mobile-phone telah berganti menjadi telepon pintar (smartphone) dan berpergian ke tempat wisata menjadi gaya hidup baru. Sebuah tourism scheduler yang dilengkapi dengan reminder, yang dapat digunakan untuk menyimpan data-data perjalanan, serta memberikan informasi-informasi tempat wisata, hotel, dan transportasi yang dibutuhkan dalam melakukan perjalanan wisata telah dihasilkan pada penelitian ini. Metode penelitian yang digunakan adalah waterfall model. Hasil yang dicapai berupa suatu aplikasi yang dapat menjadwalkan perjalanan wisata yang berdiri pada platform Blackberry, serta memberikan informasi-informasi yang dibutuhkan ketika melakukan perjalanan wisata. Fitur history yang tersedia pada aplikasi ini menjadi keunggulan yang membantu user untuk menentukan tujuan wisata baru. Selain itu aplikasi ini juga mempunyai perancangan interface yang menarik sesuai dengan delapan aturan emas.
\end{abstract}

Kata kunci: smartphone, waterfall model, pariwisata, Blackberry 


\section{PENDAHULUAN}

Indonesia adalah negara yang memiliki banyak potensi dalam bidang pariwisata, terutama karena letak yang strategis dan bentuk kepulauan. Keindahan alam yang ditawarkan oleh pulau-pulau yang ada serta masyarakat Indonesia yang ramah menjadi daya tarik tersendiri bagi para turis, baik domestik ataupun mancanegara. Seperti Gili Trawangan yang awalnya adalah sebuah pulau biasa kemudian menjadi sebuah pulau yang ingin dituju oleh para backpacker dan membuatnya menjadi sebuah pulau untuk berpesta. Fasilitas berkembang dengan sangat pesat (Hampton \& Jeyacheya, 2013). Tidak sedikit penyedia jasa wisata juga menawarkan beberapa perjalanan untuk menikmati alam Indonesia. Turis yang ingin berwisata di Indonesia dapat menggunakan jasa wisata tersebut, terutama untuk turis asing. Sedangkan untuk turis lokal yang lebih mengenal wilayah Indonesia, dapat memilih untuk berpergian dengan merencanakan jadwal perjalanan mereka masing-masing.

Bagi wisatawan yang tidak mempunyai banyak waktu untuk mempersiapkan jadwal perjalanan, travel agent siap untuk melayani melalui jadwal perjalanan yang sudah diatur baik dari segi transportasi, tempat menginap, dan konsumsi, serta dibantu dengan tour guide selama perjalanan. Namun bagi wisatawan yang ingin menggunakan jadwal perjalanan mereka sendiri maka kekurangan terbesarnya adalah tidak ada pemandu wisata di area wisata yang akan dituju. Peta menjadi salah satu solusi bagi para wisatawan yang tidak menggunakan jasa tour guide. Selain itu, buku panduan wisata juga menjadi pilihan beberapa wisatawan yang mempunyai persiapan penuh untuk perjalanan mereka. Sedangkan pada zaman sekarang, dengan adanya fasilitas jaringan internet yang memadai, beberapa wisatawan hanya mengandalkan informasi mengenai tempat wisata dengan menggunakan mobile phone.

Berkembangnya era teknologi saat ini sangat berpengaruh pesat terhadap pola hidup masyarakat dunia. Hampir setiap orang mempunyai alat komunikasi mobile phone, di mana sebagian dari teknologi mobile saat ini sudah tidak dapat dipisahkan dengan jaringan internet. Blackberry smartphone adalah pelopor aplikasi mobile yang menyediakan informasi yang real-time dengan kemampuan unggulannya yaitu push data. Terlebih lagi Blacberry merupakan platform yang paling tinggi ketahanannya (robust) serta menyediakan mekanisme standar untuk mengakses dan memanipulasi data (Oliver, 2009). Aplikasi-aplikasi yang ditawarkan juga bermanfaat seperti aplikasi Foyage dan Foursquare. Kedua aplikasi tersebut sangat membantu para wisatawan dan para pejelajah karena informasi yang disediakan seperti informasi hotel, tempat wisata, ataupun posisi keberadaan penggunanya.

Gaya hidup berpergian yang baru tersebut dan didukung dengan perkembangan zaman saat ini membuka peluang untuk dibangunnya sebuah aplikasi berbasiskan Blackberry smartphone. Dengan adanya aplikasi scheduler, pengguna tidak perlu lagi membawa kertas-kertas peta, atau mencari pemandu wisata. Pengguna dapat menyusun jadwal perjalanan dan menyimpannya ke dalam sebuah aplikasi pada Blackberry mereka dan dilengkapi dengan reminder serta informasi-informasi tambahan tentang tempat wisata yang akan dituju. Aplikasi ini akan mempermudah wisatawan untuk menyusun jadwal serta membuat seluruh wisatawan mengetahui banyak tempat wisata di Indonesia yang dapat dikunjungi.

\section{Tinjauan Pustaka}

Pembangunan sebuah aplikasi berbasiskan pada mobile platform serupa dengan pembangunan sebuah software pada embedded-application, di mana terdapat lebih banyak faktor yang perlu dipertimbangkan dibandingkan dengan pembangunan software secara tradisional (Wasserman, 2010). Interaksi potensial dengan aplikasi lainnya menjadi salah satu pertimbangan karena pada umumnya peralatan mobile mempunyai banyak sekali aplikasi yang dapat berasal dari berbagai macam sumber. 
Selain itu dalam sebuah smartphone juga terdapat sensor-handling yang dapat merespon perubahan gerakan, sentuhan, microphone, dan lainnya yang dapat diaplikasikan pada software yang dibuat. Pada umumnya aplikasi native dan hybrid (mobile web) membutuhkan service dari jaringan telepon, internet melalui web browser, yang akan memberikan efek pada data dan tampilan pada smartphone tersebut. Sedangkan untuk pemilihan sebuah platform itu sendiri, developer perlu memutuskan pada versi berapa aplikasi yang akan dibangun dapat dijalankan, mengingat ada banyak sekali versi dan sistem operasi yang dikembangkan (Fring, 2009). Beberapa faktor lain adalah masalah keamanan, perancangan tampilan pada user, kompleksitas dari uji coba, serta konsumsi daya pada mobile device tersebut. Developer perlu untuk merancangan tampilan dari aplikasi yang dapat berbagi elemen umum dari aplikasi lain dan harus memenuhi pengembangan user-guideline.

Agile process development menjadi pilihan bagi para developer dalam mengembangkan aplikasi yang memiliki kompleksitas tinggi. Salah satu process model yang dapat digunakan adalah pendekatan Scrum (Schwaber, 2001; Pressman, 2005). Pengembangan aplikasi dengan pendekatan Scrum membuat beberapa partisi dari pekerjaan-pekerjaan menjadi sebuah "paket”. Uji coba terhadap aplikasi dan dokumentasi tetap dilakukan selama proses pengembangan aplikasi berlangsung. Pendekatan ini menerapkan sistem "sprint" di mana setiap pekerjaan akan diselesaikan dalam masa waktu yang pendek dan setiap "sprint" merupakan sebuah pengerjaan dari sebuah "backlog" kebutuhan yang diperlukan. Pengembangan aplikasi pada smartphone menggunakan pendekatan Scrum disarankan bagi para developer berdasarkan survei yang telah dilakukan (Agarwal \& Wasserman, 2010).

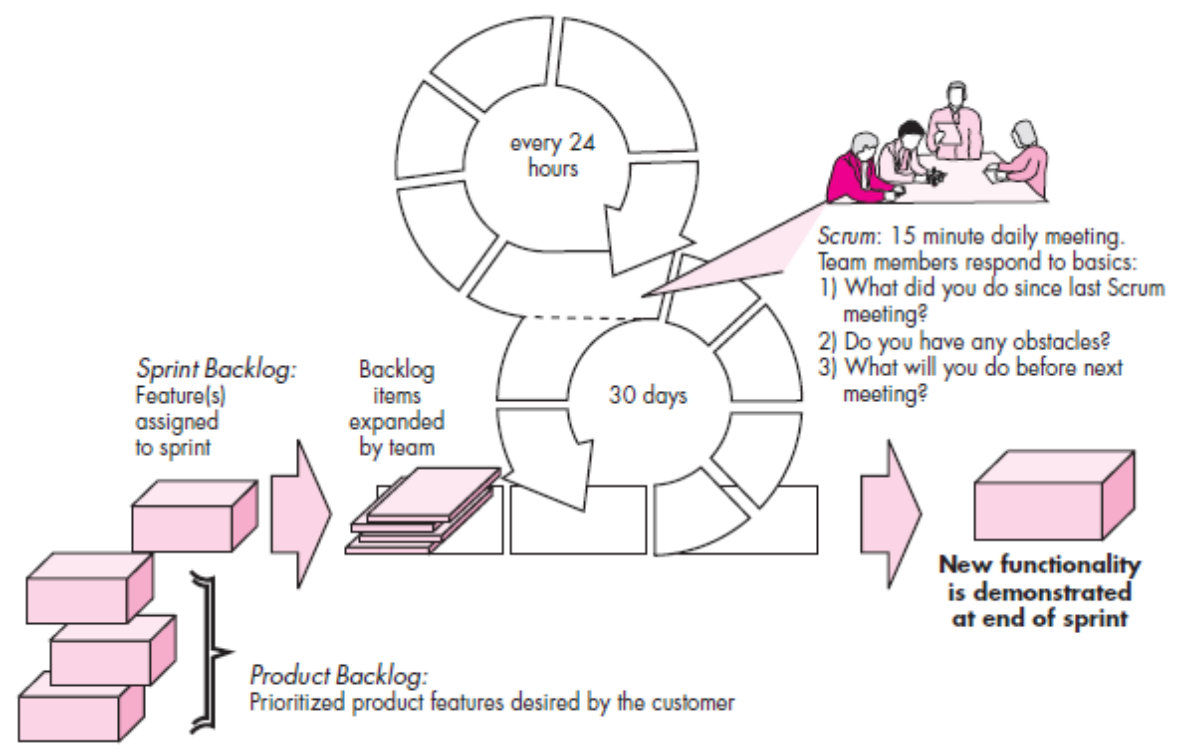

Gambar 1 Scrum process model (Pressman, 2005)

Pembangunan aplikasi wisata ini memanfaatkan teknologi J2ME dan GPS. Java2 Micro Edition atau yang biasa disebut J2ME adalah lingkungan pengembangan yang didesain untuk meletakan perangkat lunak Java pada barang elektronik beserta perangkat pendukungnya. J2ME dikhususkan untuk pengembangan perangkat lunak selain computer desktop yang biasanya lebih kecil, seperti telepon selular, pager, dan sejenisnya. J2ME dikhususkan untuk digunakan dalam perangkat dengan besar memory dan CPU yang lebih terbatas (Muchow, 2002). Sedangkan GPS digunakan untuk mengetahui keberadaan posisi wisatawan. GPS (Global Positioning System) adalah satu set satelit dan system control yang memungkinkan receiver GPS yang didesain secara spesifik 
menentukan lokasi-lokasi di setiap tempat di Bumi selama 24 jam setiap harinya. Ada dua sistem utama yaitu sistem NAVSTAR Amerika dan sistem GLONASS Rusia. Sistem Eropa juga telah direncanakan untuk dibangun dalam waktu dekat. Sistem Amerika terdiri dari 24 satelit yang berputar mengelilingi Bumi di orbit yang tinggi. Satelit-satelit ini memiliki waktu orbit 12 jam dan melewati stasiun kontrol, sehingga orbit mereka bisa dimonitor secara seksama dan posisi mereka bisa diidentifikasikan secara tepat. Satelit-satelit dan receiver yang berada di Bumi mengirim radio sinyal yang sama, sehingga penangguhan waktu antara pengiriman dan penerimaan sinyal memberitahukan jarak antara satelit dan receiver. Jika receiver dapat mengambil sinyal dari tiga atau empat satelit, digunakan trigonometri untuk menghitung lokasi dan ketinggian receiver (Heywood, Cornelius \& Carver).

\section{METODE}

Sebuah proses pembangunan aplikasi selalu dimulai dengan proses pengumpulan kebutuhan, apapun jenis pendekatan yang digunakan. Pendekatan Scrum diterapkan dalam mengembangkan aplikasi ini, di mana sebelum setiap sprint dimulai maka ada beberapa proses yang dilakukan seperti ditunjukan pada gambar 2, yang terdiri dari requirement engineering dan requirement modeling. Tujuan dari proses tersebut adalah untuk menentukan fitur apa saja yang akan dibangun pada aplikasi wisata ini. Kuisioner menjadi pilihan dalam riset ini untuk menganalisa kebutuhan pasar. Terdapat 45 orang calon user yang berkontribusi dalam memberikan ide/masukan/pendapat mereka di mana ada beberapa pertanyaan yang membantu mereka dalam menyalurkan kebutuhan tersebut. Tabel 1 memperlihatkan beberapa pertanyaan beserta dengan tujuan dari pertanyaan tersebut bagi developer dalam menentukan fitur yang dibutuhkan.

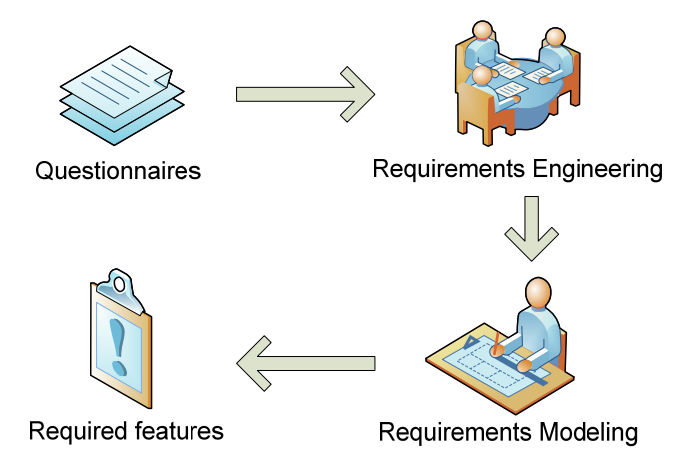

Gambar 2 Workflow process

Dari kuisioner yang telah dikumpulkan maka akan dilakukan pertemuan antara project manager dengan developer. Analisis dilakukan untuk mengumpulkan informasi atas apa yang diharapkan dari calon user untuk membantu mereka dalam melakukan wisata. Use-case diagram akan dihasilkan dari tahapan requirements modeling, di mana fitur-fitur yang akan dibangun dapat dilihat pada diagram tersebut. Pada tahapan modeling, untuk merancang aplikasi yang akan dibuat maka use case diagram digunakan. 
Tabel 1 Pengumpulan informasi calon user

\begin{tabular}{|c|c|c|}
\hline No. & Pertanyaan & Tujuan pertanyaan \\
\hline 1 & Seberapa sering Anda berwisata? & Memperkirakan jumlah user. \\
\hline 2 & Prioritas tempat yang dikunjungi. & $\begin{array}{l}\text { Mengumpulkan informasi tempat untuk merancang } \\
\text { fitur yang dibutuhkan. }\end{array}$ \\
\hline 3 & $\begin{array}{l}\text { Lebih suka ikut travel atau mengatur jadwal } \\
\text { perjalanan sendiri. }\end{array}$ & $\begin{array}{l}\text { Mengetahui jumlah responden yang akan } \\
\text { memanfaatkan aplikasi yang dibangun. }\end{array}$ \\
\hline 4 & Kendala ketika mengikuti travel. & $\begin{array}{l}\text { Membuat aplikasi yang akan meminimalisir } \\
\text { kekurangan dari program tour. }\end{array}$ \\
\hline 5 & $\begin{array}{l}\text { Kendala ketika mengatur jadwal perjalanan } \\
\text { sendiri. }\end{array}$ & $\begin{array}{l}\text { Membuat aplikasi yang akan menjadi solusi dari } \\
\text { masalah. }\end{array}$ \\
\hline 6 & $\begin{array}{l}\text { Pertimbangan informasi yang diperlukan dalam } \\
\text { mengatur jadwal perjalanan sendiri. }\end{array}$ & $\begin{array}{l}\text { Mengetahui fitur yang dibutuhkan langsung dari } \\
\text { konsumer. }\end{array}$ \\
\hline 7 & $\begin{array}{l}\text { Kapan Anda mengatur jadwal perjalanan? } \\
\text { (sebelum/sesudah sampai ditempat wisata) }\end{array}$ & Mengetahui sistem penjadwalan yang diharapkan. \\
\hline 8 & $\begin{array}{l}\text { Lebih nyaman menggunakan peta cetak atau } \\
\text { digital untuk mencari tempat yang dituju? }\end{array}$ & $\begin{array}{l}\text { Mengetahui kenyamanan responden dalam } \\
\text { menggunakan peta digital yang akan digunakan } \\
\text { dalam aplikasi yang dibangun. }\end{array}$ \\
\hline 9 & $\begin{array}{l}\text { Pernakah Anda menggunakan aplikasi mobile } \\
\text { yang berkaitan dengan wisata? }\end{array}$ & $\begin{array}{l}\text { Untuk memperkirakan jumlah user yang akan } \\
\text { menggunakan aplikasi yang dibangun. }\end{array}$ \\
\hline
\end{tabular}

Setelah perancangan telah selesai dilakukan, maka fitur-fitur yang ada dalam rancangan tersebut akan mulai dibangun. Proses dalam pembangunan dari setiap fitur dengan menggunakan metode Scrum yang ditunjukkan pada gambar 1. Setiap fitur yang dirancang merupakan sebuah backlog yang akan dikerjakan dalam 1 sprint, di mana untuk 1 sprint ditargetkan untuk selesai dalam waktu 14 hari kerja. Pada akhir sprint dilakukan demonstrasi terhadap perkembangan aplikasi yang ada. Pada pertemuan tersebut akan dibahas juga mengenai hambatan yang dihadapi selama pengerjaan dan bagaimana cara pemecahan masalah yang ada tersebut, serta apa saja perkembangan yang harus dilakukan untuk pertemuan berikutnya. Dengan dilakukannya beberapa kali sprint maka aplikasi wisata ini dapat terselesaikan dengan baik. Di setiap sprint itu sendiri juga tidak menutup kemungkinan developer akan berdiskusi bersama dengan project manager tentang kesulitan-kesulitan yang dihadapi dan ide solusinya.

Developer sendiri menerapkan sistem pemrograman yang dinamis, yaitu merupakan suatu teknik analisa kuantitatif untuk membuat tahapan keputusan yang saling berhubungan. Teknik ini menghasilkan prosedur yang sistematis untuk mencari keputusan dengan kombinasi yang optimal. Pemograman dinamis sebagai permasalahan menjadi beberapa tahapan keputusan, di mana hasil keputusan membagi masalah menjadi beberapa tahapan keputusan dari tiap-tiap tahapan selanjutnya. Selain itu, pemograman dinamis juga mempunyai kemampuan untuk mencari solusi optimal dari suatu permasalahan menjadi beberapa masalah dalam satuan waktu yang lebih kecil.

\section{HASIL DAN PEMBAHASAN}

Penerapan pendekatan Scrum sangat efektif dalam pengembangan aplikasi wisata ini. Dengan metode "sprint" yang diterapkan memudahkan bagi para developer untuk membahas kebutuhan yang perlu dikembangkan, dimodifikasi, diperbaiki, ataupun ditambahkan berdasarkan dari hasil evaluasi setiap tahapan. Namun demikian sebelum memulai tahapan Scrum maka diperlukan proses pengumpulan kebutuhan agar dapat menentukan fitur yang akan dibangun. Kuesioner adalah salah satu cara yang paling tepat dalam melakukan analisa kebutuhan pasar sehingga produk aplikasi yang dihasilkan nantinya tepat sasaran dan dapat dimanfaatkan sebagai solusi dari permasalahan yang ada. 


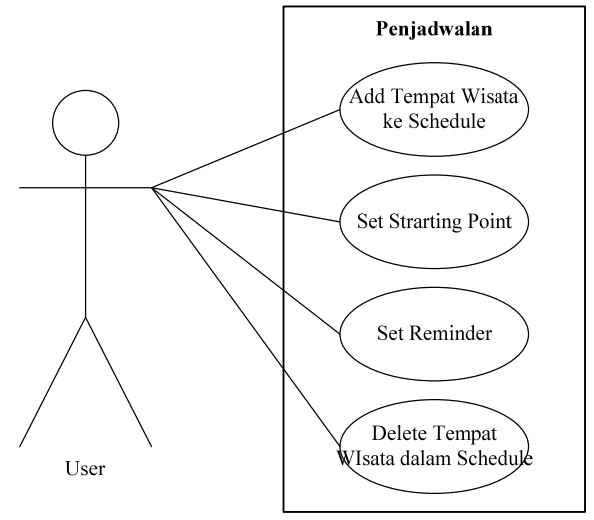

Gambar 3 Use Case diagram dari penjadwalan wisata

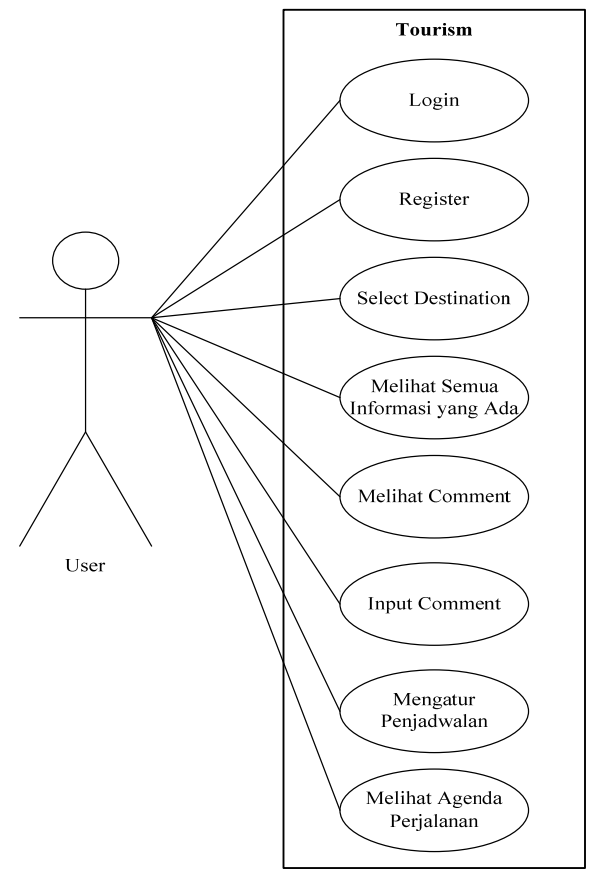

Gambar 4 Use Case diagram dari informasi wisata

Berdasarkan analisis requirement engineering dan requirement modeling tersebut maka terdapat dua fitur utama yang akan dibangun yaitu penyusunan jadwal perjalanan wisata dan catatan perjalan wisata, beserta dengan informasi tempat-tempat pariwisata yang ada di kota tujuan. Representasi dari sistem tersebut dapat dilihat pada gambar 3 dan 4. Fitur utama dari aplikasi ini adalah penjadwalan, di sini user dapat membuat jadwal perjalanan trip sendiri. Fungsi-fungsi yang akan dibangun yaitu menambah dan menghapus data tempat wisata ke dalam aplikasi serta membuat pengingat.

Sedangkan untuk fitur informasi wisata, aplikasi ini akan meminta user untuk dapat melakukan registrasi terlebih dahulu dan login ke dalam sistem. Kemudian user dapat melakukan pencarian terhadap tempat wisata yang dituju dan melihat informasi yang ada beserta dengan komentar-komentar dari wisatawan lain. User juga dapat memasukkan komentar seperti user lain dan dapat membuat agenda perjalanan sendiri. 
Pengembangan aplikasi wisata ini diterapkan dengan menggunakan teknologi mobile BlackBerry terdiri dari dua server dan satu mobile BlackBerry smartphone. Berikut ini merupakan spesifikasi yang disarankan untuk server:
Prosesor $\quad$ : Intel@ Pentium ${ }^{\circledR}$ Dual CPU E2200 @ 2.20GHz 2.22GHz
Memori $\quad: 1,99 \mathrm{~GB}$
VGA : OnBoard
Hardisk : $160 \mathrm{~GB}$
Input $\quad$ : Keyboard dan Mouse
Output : Monitor 17 inch

Minimal spesifikasi mobile BlackBerry untuk aplikasi penjadwalan wisata adalah BlackBerry Gemini.

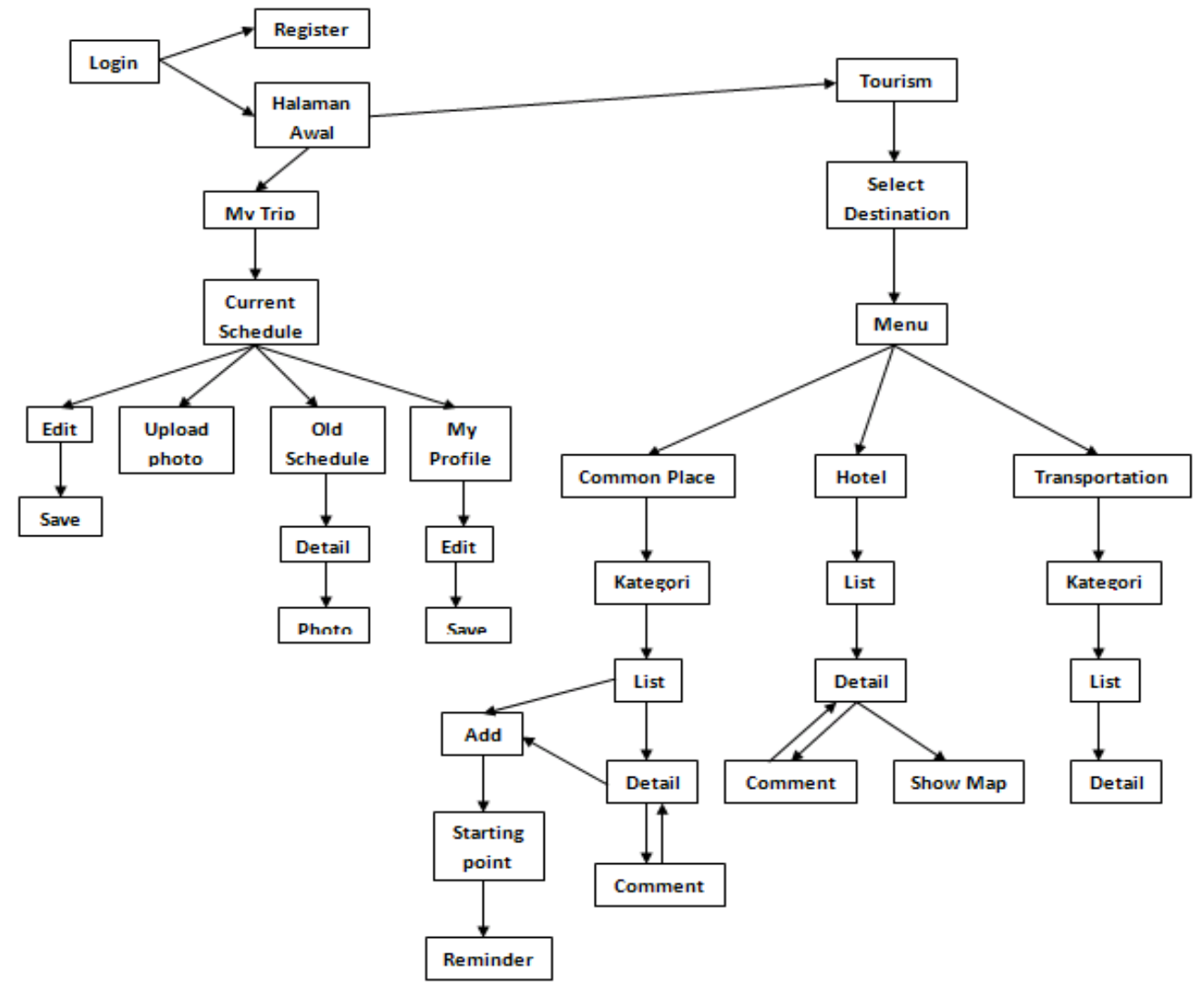

Gambar 3 Diagram Alur Aplikasi

Sedangkan untuk spesifikasi perangkat lunak yang diperlukan untuk menjalankan aplikasi penjadwalan wisata dengan menggunakan teknologi mobile BlackBerry adalah sebagai berikut:

Spesifikasi untuk server

Sistem Operasi : : Windows 7 Professional

Aplikasi Server $\quad$ : Apache web server, PHP, MySql

Spesifikasi untuk mobile BlackBerry

Sistem Operasi $\quad$ : BlackBerry OS 5.0 
User interface merupakan salah satu faktor tambahan penting yang membedakan antara aplikasi berbasiskan mobile dengan desktop (Wasserman, 2010). Oleh karena itu evaluasi dari sudut pandang perancangan interface dilakukan dengan mengikuti aturan dari 8 aturan emas (8 Golden rules) (Shneiderman \& Plaisant, 2010), yaitu sebagai berikut: (1) Konsistensi; pada aplikasi penjadwalan wisata, perancangan dibuat agar dapat mempertahankan konsistensi dari segi tampilan maupun penggunaan layout, huruf dan warna. Hal tersebut dapat dilihat dari halaman muka serta halaman-halaman berikutnya. (2) Memenuhi Kebutuhan Menyeluruh; aplikasi yang dibangun untuk BlackBerry smartphone ini dapat digunakan oleh siapa saja dan oleh seri BlackBerry smartphone apa saja. (3) Memberikan Umpan Balik yang Informatif; Perancangan aplikasi penjadwalan wisata dibuat sedemikian rupa sehingga sistem akan mengirimkan umpan balik pada setiap aksi yang diberikan oleh user. Sebagai contoh,user diberikan peringatan pada setiap aksi yang dilakukannya, seperti peringatan saat akan menghapus data perjalanan yang lama. (4) Dialog untuk Keadaan Akhir; Perancangan aplikasi penjadwalan wisata dibuat sedemikian rupa sehingga user dapat mengetahui keadaan akhir dari aksi yang sedang dijalankan. Sebagai contoh, pada saat melakukan pergantian pada jadwal, akan ada kotak dialog yang memberi tahu bahwa jadwal sudah diganti dengan sukses. (5) Pencegahan Kesalahan; pada aplikasi penjadwalan wisata dapat dilihat pada halaman Register di bagian pengisian password, terdapat pesan sebagai salah satu pencegahan kesalahan saat memasukkan password. (6) Pembalikan Aksi yang Sederhana; perancangan aplikasi penjadwalan wisata dibuat sedemikian rupa agar dapat membatalkan aksi yang telah dilakukan. Sebagai contoh, pada aplikasi, ketika user menambahkan tempat wisata ke dalam jadwal dengan mengklik tombol “+”, akan muncul tanda " $\mathrm{x}$ " untuk membatalkan penambahan tersebut. (7) Mendukung Pusat Kendali Internal; dalam aplikasi penjadwalan wisata ini, user yang mengoperasikan dan menguasai sistem. Sistem akan memberikan respon sesuai aksi user. Contohnya pada bagian list, akan ada pilihan view by "Most Visited" atau "AZ”. (8) Mengurangi Beban Ingatan Jangka Pendek; pada aplikasi penjadwalan wisata dapat dilihat dari halaman pencarian jadwal transportasi, kota asal keberangkatan sudah langsung terisi berdasarkan kota tujuan yang dipilih saat sesudah login, namun juga bisa diganti secara manual.

Evaluasi dari sisi fungsionalitas aplikasi ini diperoleh dengan cara meluncurkan kuesioner kembali kepada 54 responden yang berbeda atau responden yang juga berkonstribusi sebelumnya pada tahap requirement engineering. Berikut adalah hasil dari kuesioner yang disebar ke 54 responden: (1) Dengan adanya aplikasi penjadwalan wisata, apakah memungkinkan untuk mengatur kunjungan wisata anda tanpa dibantu oleh travel? 28 dari 54 responden (52\%) menjawab bahwa dengan adanya aplikasi penjadwalan wisata ini, memungkinkan untuk mengatur kunjungan wisata tanpa dibantu oleh travel agent. (2) Apakah dengan reminder yang disediakan untuk penjadwalan wisata, membantu Anda mengatur waktu anda selama dalam perjalanan wisata? 31 dari 54 responden (57\%) menjawab bahwa dengan reminder yang disediakan dalam penjadwalan wisata, dapat membantu dalam mengatur waktu dalam perjalanan wisata. (3) Apakah informasi wisata yang disediakan dalam aplikasi ini sudah lengkap? 33 dari 54 responden (61\%) menjawab bahwa informasi yang disediakan dalam aplikasi ini sudah lengkap. (4) Apakah fitur history wisata membantu Anda dalam menentukan tujuan wisata baru? 52 dari 54 responden (96\%) menjawab bahwa fitur history wisata dapat membantu dalam menentukan tujuan wisata baru. (5) Apakah tampilan aplikasi penjadwalan wisata ini mudah dimengerti bagi Anda? 37 dari 54 responden (69\%) menjawab bahwa tampilan aplikasi ini mudah dimengerti.

Umpan balik dari pengguna menunjukkan bahwa sebagian pengguna bisa memanfaatkan aplikasi pada smartphone ini untuk membuat jadwal perjalanan mereka tanpa melibatkan travel-agent. Kelebihan yang disediakan pada aplikasi ini, yaitu reminder, cukup membantu untuk wisatawan untuk mengingat jadwal keberangkatan perjalanan wisatawan. Namun demikian, para pengguna merasa bahwa informasi yang ada dalam aplikasi ini belum cukup lengkap. Selain itu, fitur history yang disediakan adalah fitur paling diminati oleh para pengguna (96\%) karena dapat melihat tempat-tempat wisata untuk perjalanan mereka yang baru. Dari segi tampilan, 69\% pengguna dapat mudah menggunakan aplikasi ini, tetapi 31\% masih kesulitan dalam menggunakannya. Adapun perbandingan fitur-fitur yang dimiliki oleh aplikasi ini dengan aplikasi sejenis dapat dilihat pada tabel 2. 
Tabel 2 Perbandingan aplikasi sejenis

\begin{tabular}{|c|c|c|c|c|c|}
\hline Fitur & Foyage & 4square & $\begin{array}{c}\text { BB map/ } \\
\text { Googlmap }\end{array}$ & Tungle & $\begin{array}{l}\text { Tourism } \\
\text { Scheduler }\end{array}$ \\
\hline \multicolumn{6}{|l|}{ Tempat umum } \\
\hline Hotel & ada & ada & ada & tidak & ada \\
\hline Karaoke & ada & ada & ada & tidak & ada \\
\hline Café & ada & ada & ada & tidak & ada \\
\hline Fast food & ada & ada & ada & tidak & ada \\
\hline Coffee shop & ada & ada & ada & tidak & ada \\
\hline Mall & ada & ada & ada & tidak & ada \\
\hline Bar & ada & ada & ada & tidak & ada \\
\hline Restoran & ada & ada & ada & tidak & ada \\
\hline Museum & tidak & ada & ada & tidak & ada \\
\hline Arena rekreasi & tidak & ada & ada & tidak & ada \\
\hline Rumah sakit & tidak & ada & ada & tidak & tidak \\
\hline Bakery & ada & ada & ada & tidak & tidak \\
\hline Petrol kiosk & ada & ada & tidak & tidak & tidak \\
\hline Sekolah/Kampus & tidak & ada & ada & tidak & tidak \\
\hline Stall & ada & ada & ada & tidak & tidak \\
\hline ATM & ada & ada & ada & tidak & tidak \\
\hline Bioskop & ada & ada & ada & tidak & tidak \\
\hline Pencarian lokasi & ada & ada & ada & tidak & ada \\
\hline Show on map & ada & ada & ada & tidak & ada \\
\hline \multicolumn{6}{|l|}{ Informasi tempat } \\
\hline alamat & ada & ada & ada & tidak & ada \\
\hline no. telepon & ada & tidak & ada & tidak & ada \\
\hline rating & ada & ada & ada & tidak & tidak \\
\hline tempat terdekat & ada & ada & ada & tidak & tidak \\
\hline Menambahkan lokasi & tidak & ada & tidak & tidak & tidak \\
\hline Comment & ada & ada & tidak & tidak & ada \\
\hline Fasilitas & tidak & tidak & tidak & tidak & ada \\
\hline Foto lokasi & tidak & tidak & tidak & tidak & ada \\
\hline Info transportasi & tidak & tidak & tidak & tidak & ada \\
\hline Penjadwalan wisata & tidak & tidak & tidak & ada & ada \\
\hline Rekomendasi & tidak & tidak & tidak & tidak & ada \\
\hline
\end{tabular}

\section{SIMPULAN}

Scrum adalah metode yang tepat dalam melakukan pengembangan aplikasi mobile karena sifatnya yang cepat menghadapi perubahan terhadap requirement ataupun permasalahan yang muncul. Selain itu yang membuat Scrum menjadi pilihan yang tepat adalah perkembangan teknologi terutama pada smartphone terus berkembang dengan cepat. Bila aplikasi mobile yang sedang dibangun saat ini tidak diselesaikan dengan cepat, maka akan tertinggal dengan aplikasi lainnya yang menggunakan teknologi lebih baru. Perumusan kebutuhan dengan menggunakan kuesioner sebaiknya dilakukan untuk pengumpulan kebutuhan pasar, akan tetapi ada baiknya bila dilakukan wawancara singkat kepada beberapa calon user agar fungsionalitas yang dibangun lebih tepat sasaran dan akan digunakan oleh user yang lebih besar lagi.

Aplikasi penjadwalan wisata ini sendiri memungkinkan orang-orang pergi berwisata tanpa dibantu travel agent. Fitur-fitur serta kemudahan yang disediakan dalam aplikasi penjadwalan wisata ini membantu user dalam melakukan perjalanan wisata sehingga meningkatkan jumlah wisatawan yang berwisata di Indonesia. Kelengkapan informasi yang disediakan dalam aplikasi ini dapat menjadi pertimbangan dalam memilih tempat tujuan wisata, terutama daerah-daerah wisata dalam negeri yang mempunyai daya tarik bagi para wisatawan. 
Untuk menyempurnakan aplikasi penjadwalan wisata yang telah dirancang agar dapat berjalan dengan lebih baik lagi maka diperlukan beberapa usaha pengembangan lebih lanjut, diantaranya adalah penambahan pilihan bahasa (multi language), penambahan fitur pemesanan tiket untuk pesawat dan pemesanan kamar hotel, serta penambahan fitur yang tersambung dengan social networking.

\section{DAFTAR PUSTAKA}

Agarwal, S., A.I. Wasserman. (2010). Mobile Application Development: A Developer Survey. Submitted for publication.

1

Fring, B.(2009). Mobile Design and Development. O’Reilly.

Hampton, M. P., Jeyacheya, J. (2013) Bio-rock and roll? Dive Tourism and Island Communities: the case of Gili Trawangan, Indonesia. In: Second IGU Conference on Coastal, Island and Tropical Tourism incorporating the Second International Dive Tourism Expert Meeting, 2224 April 2013, Kota Kinabalu, Malaysia.

Heywood, I., Cornelius, S., Carver, S. (2002). An Introduction to Geographical Information Systems. $2^{\text {nd }}$ Edition. Harlow: Prentice Hall.

Muchow, J. W.(2002). Core J2ME Technology \& MIDP. Amerika: The Sun Microsystem Press.

Oliver, E. (2009). A survey of platforms for mobile networks research. ACM SIGMOBILE Mobile Computing and Communications Review, 12.4: 56-63.

Pressman, R. S. (2005). Software Engineering : A Practitioner's Approach. $6^{\text {th }}$ Edition. Hill: Mc Graw.

Schwaber, K. (2004). Agile Project Management with Scrum. Microsoft Press.

Shneiderman, B., Plaisant, C. (2010). Designing The User Interface. $5^{\text {th }}$ Edition. Pearson Higher Education.

Wasserman, A. I. (2010). Software engineering issues for mobile application development. Proceedings of the FSE/SDP workshop on Future of software engineering research. ACM. 